\title{
INVITED EDITORIAL ON "EFFECTS OF GLUTAMATE AND ASPARTATE ON MYOCARDIAL SUBSTRATE OXIDATION DURING POTASSIUM ARREST"
}

\author{
Gerald D. Buckberg, MD
}

T he manuscript by Reed and colleagues about the effect of glutamate and aspartate on myocardial substrate oxidation in isolated rat hearts was carried out with great biochemical expertise. The data after 30 minutes of perfusion show complete recovery of function in all perfused hearts, whether beating or arrested, with and without uptake of glutamate and aspartate. In a crystalloid preparation, there was negligible uptake of glutamate and aspartate. They observed that aspartate enters the Krebs pathway via acetyl coenzyme A; yet the standard deviation in Table III of unlabeled sources is $19 \pm 18$ and may not account for this offset directly.

The isolated rat heart was exposed to continuous oxygenated crystalloid perfusion for 30 minutes. This lowered control oxygen consumption rate from $53 \pm 10$ to 22 and $17 \mu \mathrm{mol} / \mathrm{gm}$ dry weight. This $60 \%$ fall in small hearts is substantially lower than that in working and arrested larger dog and pig hearts, in which oxygen uptake is reduced $90 \%$. More important, the smaller heart took up as much oxygen with potassium as with potassium plus glutamate cardioplegia, which indicates that the $95 \%$ perfusate oxygen provided sufficient nutrition to avoid ischemia when glutamate and aspartate were used and functioned well in all preparations. I presumed that no unhealthy hearts during the stabilization period were discarded for reasons cited below.

Most prior studies show that glutamate/aspartateenriched cardioplegic solution improves function in metabolism only in injured hearts. Studies of intermittent oxygenated crystalloid solution in isolated rat hearts show that uptake of glucose and branch chain acids enhanced myocardial function, ${ }^{1}$ delayed postischemic contracture, raised adenosine triphos-

From the University of California at Los Angeles School of Medicine, Los Angeles, Calif.

Requested for publication June 24, 1996; received for publication July 25, 1996; accepted for publication August 2, 1996.

Address for reprints: Gerald D. Buckberg, MD, Department of Cardiothoracic Surgery, UCLA Medical Center, Rm. B2-375 CHS, 10833 Le Conte Ave., Los Angeles, CA 90095-1741. J Thorac Cardiovase Surg 1996;112:1661-3

Copyright (C) 1996 by Mosby-Year Book, Inc.

$0022-5223 / 96 \$ 5.00+0 \quad \mathbf{1 2 / 1 / 7 7 1 4 7}$

phate and creatinine phosphate levels, reduced lactate dehydrogenase release after reperfusion, and confirmed this in phosphorus 31-nuclear magnetic resonance studies. ${ }^{2}$ Specific amino acid effects could not be defined. The blockade of transamination by amino oxyacetate avoids the benefits of amino acids during intermittent ischemia, ${ }^{3}$ and my colleagues and $\mathrm{I}^{4}$ have confirmed this after hypoxia in infant dog hearts with the use of a blood cardioplegic solution.

Pisarenko and coworkers, ${ }^{5}$ in isolated intermittently perfused rat hearts, showed that glutamate cardioplegia lessens ammonium accumulation, increases lactate utilization, and improves high-energy phosphates. Similar findings after precardioplegic ischemia were found by Kimose and associates, ${ }^{6}$ including the marked loss of glutamate in the reperfusate in blood-perfused hearts (to be considered subsequently). We showed augmented glutamateaspartate uptake after brain death in $\operatorname{dogs}^{7}$ and in hypoxic infant hearts, ${ }^{8}$ with no changes after blood cardioplegia without preceding ischemia. Rau and coworkers $^{9}$ observed that glutamate, aspartate, arginine, and orthinine, all of which are associated with the malate-aspartate shuttle, improved posthypoxic function in rabbit hearts. This may be the primary way to transfer equivalents across the mitochondrial membrane and regulate $\mathrm{NAD} / \mathrm{NADH}$ (nicotinamide adenine dinucleotide and nicotinamide adenine dinucleotide reduced form) balance. Choong and Gavin ${ }^{10}$ evaluated hypothermic St. Thomas' Hospital cardioplegic solution with L-aspartate. Storage with this solution allowed full recovery of left ventricular function and reduced sodium and calcium uptake and high-energy phosphate decline after 10 hours. The effects were extended to 20 hours with low perfusion pressure. These electrolyte effects may be important. Lazar and associates ${ }^{11}$ showed that adding glutamate to the storage solutions provided better results than oxygen-derived free radical scavengers (superoxide dismutase and catalase) after 5 hours $^{2}$ storage of rabbit hearts. Engelman and colleagues ${ }^{12}$ studied regional ischemia lasting 60 minutes and showed that adding glutamate and aspartate to the car- 
dioplegic solution produced better contractile function in the ischemic segment than in controls. We have shown this experimentally and clinically, but other electrolyte cardioplegic effects, especially hypocalcemia, may have contributed to the results.

The major finding is the relative absence of citric acid effects on oxygenated perfused rat hearts with low energy requirements. Our studies confirm this with intermittent blood cardioplegia with and without amino acids. There was no change in oxygen uptake, left ventricular compliance, or contractility after 3 to 4 hours of ischemia. ${ }^{13-15}$ We also used only cold glutamate, and we suspect that it acted postischemically to replace Krebs cycle intermediates lost during ischemia. ${ }^{14}$ Our use is only during warm induction and reperfusion (5 minutes each). Rosenkranz and colleagues ${ }^{15}$ needed to study ischemia plus 5 minutes of reperfusion to confirm that glutamate and aspartate enrichment improved initial oxygen uptake, lessened anaerobic metabolism, and restored left ventricular function nearly completely. The major change of ischemia is defined under the area of study limitations, because many urgent operations are done in patients with ischemic and reperfusion damage.

Pisarenko, Lepilin, and Ivanov ${ }^{16}$ demonstrated in patients receiving high-dose dopamine that glutamate changed lactate production to consumption, reduced ammonia, showed a fivefold increase in glutamate uptake, and improved cardiac function by intravenous infusion of glutamate without changing oxygen demands. No control studies with volume infusion were made. Similar data by Thomassen and colleagues ${ }^{17}$ showed that intravenous glutamate reduced ischemic threshhold by pacing by decreasing ST-segment depression, lowering lactate release, reducing fatty acid content by $20 \%$, and raising myocardial glutamate uptake by $25 \%$. Svedjeholm and associates, ${ }^{18-20}$ following up patients who had coronary bypass, showed glutamate release during reperfusion. They demonstrated that intravenous glutamate with glucose-insulin-potassium increased myocardial oxygen uptake of glutamate and lactate and improved cardiac performance. The change to lactate production was presumed to be due to improvement in oxygen metabolism by glutamate. This group showed also evaluated the use of glutamate and glucose-insulin-potassium in patients with coronary disease who have depressed cardiac function. They showed that adding these components after reperfusion but during bypass allows recovery and frequently avoids inotropic intervention by im- proving postoperative cardiac output metabolically. ${ }^{21}$

Clearly, crystalloid cardioplegic solutions are more simple and economical to use than blood solutions. They relate to specific species. Alternatively, there are no blood components (protein, erythrocytes, leukocytes, platelets), and concentrations of ions like calcium and magnesium are different from those in blood cardioplegic solutions. They also must have higher oxygen tensions, which may be detrimental. Qui and Hearse ${ }^{22}$ stated that blood perfusion should be used more frequently. For example, as stated in this study, insulin promotes uptake of amino acids by the heart and skeletal muscle in vitro. ${ }^{23,24}$ Aoki $^{25}$ demonstrated that uptake of glutamate by insulin occurs only in the whole blood analyses and allowed direct passage to extracellular fluids.

It is possible that the literature cited related to substrate and ischemic hearts and differences in cardioplegic solution used, together with the acetyl coenzyme A, analyses may be different from the experimental and clinical effects of amino acid supplementation shown by others. The carbon 13nuclear magnetic resonance spectroscopy is superb. It is important to repeat these studies in an in vivo blood-perfused ischemic preparation before concluding that the amino acid benefits seen by several groups are not related to augmentation of the citric acid cycle, predominantly after reperfusion, when the heart resumes aerobic work to maintain cardiac output.

\section{REFERENCES}

1. Schwalb H, Izhar U, Yaroslavsky E, Borman JB, Uretzky G. The effect of amino acids on the ischemic heart. $\mathbf{J}$ Thorac Cardiovase Surg 1989;98:551-6.

2. Schwalb H, Kushnir T, Navon G, Yaroslavsky E, Borman JB, Uretzky $G$. The protective effect of enriched branched chain amino acid formulation in the ischemic heart: a phosphorus-31 nuclear magnetic resonance study. J Mol Cell Cardiol 1987;19:991-8.

3. Bush LR, Warren S, Mesh CL, Lucchesi BR. Comparative effects of aspartate and glutamate during myocardial ischemia. Pharmacology 1981;23:297-304.

4. Julia P, Young HH, Buckberg GD, Kofsky ER, Bugyi HI. Studies of myocardial protection in the immature heart. II. Evidence for importance of amino acid metabolism in tolerance to ischemia. J Thorac Cardiovasc Surg 1990;100:888-95.

5. Pisarenko OI, Solomatina ES, Studneva IM, Ivanov VE, Kapelko VI, Smirnov VN. Protective effect of glutamic acid on cardiac function and metabolism during cardioplegia and reperfusion. Basic Res Cardiol 1983;78:534-43.

6. Kimose HH, Ravkilde J, Helligso P, et al. Myocardial loss of glutamate after cold chemical cardioplegia and storage in 
isolated blood-perfused pig hearts. Thorac Cardiovasc Surg 1993;41:93-100.

7. Tixier D, Matheis G, Buckberg GD, Young HH. Donor hearts with impaired hemodynamics: benefit of warm substrate enriched blood cardioplegia induction during cardiac harvesting. J Thorac Cardiovasc Surg 1991;102:207-14.

8. Julia P, Young HH, Buckberg GD, Kofsky ER, Bugyi HI. Studies of myocardial protection in the immature heart. IV. Improved tolerance of immature myocardium to hypoxia and ischemia by intravenous metabolic support. $\mathrm{J}$ Thorac Cardiovasc Surg 1991;101:23-32.

9. Rau ER, Shine KI, Gervais A, Douglas AM, Amos EC. Enhanced mechanical recovery of anoxic and ischemic myocardium by amino acid perfusion. Am J Physiol 1979;236: H873-9.

10. Choong YS, Gavin JB. L-Aspartate improves the functional recovery of explanted hearts sotred in St. Thomas' Hospital cardioplegic solution at $4^{\circ} \mathrm{C}$. J Thorac Cardiovasc Surg 1990;99:510-7.

11. Lazar HL, Yang X, Rivers S, Stockwell D, Shemin RJ. Superiority of substrate enhancement over oxygen free radical scavengers during extended periods of cold storage for cardiac transplantation. Surgery 1990;108:423-30.

12. Engelman RM, Rousou JA, Flack JE, Iyengar J, Kimura Y, Das DK. Reduction of infaret size by systemic amino acid supplementation during reperfusion. J Thorac Cardiovasc Surg 1991;101:855-9.

13. Robertson JM, Vinten-Johansen J, Buckberg GD, Follette DM, Maloney JV Jr. Safety of prolonged aortic clamping with blood cardioplegia. I. Glutamate enrichment in normal hearts. J Thorac Cardiovasc Surg 1984;88:395-401.

14. Rosenkranz ER, Okamoto F, Buckberg GD. The safety of prolonged aortic clamping with blood cardioplegia. II. Glutamate enrichment in energy-depleted hearts. J Thorac Cardiovase Surg 1984;88:401-10.

15. Rosenkranz ER, Okamoto F, Buckberg GD, Robertson JM, Vinten-Johansen J, Bugyi HI. Safety of prolonged aortic clamping with blood cardioplegia. III. Aspartate enrichment of glutamate-blood cardioplegia in energy-depleted hearts after ischemic and reperfusion injury. J Thorac Cardiovasc Surg 1986;91:428-35.

16. Pisarenko OI, Lepilin MG, Ivanov VE. Cardiac metabolism and performance during L-glutamic acid infusion in postoperative cardiac failure. Clin Sci 1986;70:7-1212.

17. Thomassen A, Nielsen TT, Bagger JP, Pedersen AK, Henningsen $P$. Anti-ischemic and metabolic effects of glutamate during pacing in patients with stable angina pectoris secondary to either coronary artery disease or syndrome $\mathrm{x}$. Am J Cardiol 1991;68:291-5.

18. Svedjeholm R, Svensson S, Ekroth R, et al. Trauma metabolism and the heart: studies of heart and leg amino acid flux after cardiac surgery. Thorac Cardiovasc Surg 1990;38:1-5.

19. Svedjeholm R, Ekroth R, Joachimsson PO, Ronquist G, Svensson S, Tyden H. Myocardial uptake of amino acids and other substrates in relation to myocardial oxygen consumption four hours after cardiac operation. J Thorac Cardiovase Surg 1991;101:688-94.

20. Svedjeholm R, Vanhanen I, Håkanson E, Joachimsson PO, Jorfeldt L, Nilsson L. Metabolic and hemodynamic effects of intravenous glutamate infusion early after coronary operations. J Thorac Cardiovasc Surg In press.

21. Svedjeholm R, Huljebrant I, Håkanson E, Vanhanen I. Glutamate and high-dose glucose-insulin-potassium (GIK) in the treatment of severe cardiac failure after cardiac operations. Ann Thorac Surg 1995;59:S23-30.

22. Qiu Y, Hearse DJ. Comparison of ischemic vulnerability and responsiveness to cardioplegic protection in crystalloid-perfused vs. blood-perfused hearts. J Thorac Cardiovasc Surg 1992;103:960-8.

23. Rannels DE, Kao R, Morgan HE. Effect of insulin on protein turnover in heart muscle. J Biol Chem 1975;250: 1694-701.

24. Jefferson LS, Rannels DE, Munger BL, Morgan HE. Insulin in the regulation of protein turnover in heart and skeletal muscle. Fed Proc 1974;33:1098-104.

25. Aoki TT, Brennan MF, Muller WA, Moore FD, Cahill GF Jr. Effect of insulin on muscle glutamate uptake. J Clin Invest 1972;51:2889-94. 